\title{
Explicit-Implicit Option for the Communicative Competence in Expatriation Training under the "Belt and Road Initiative"
}

\author{
Bingbing AI \\ The International Business School \\ Yunnan University of Finance and Economics \\ Kunming, PRC \\ 870646179@qq.com
}

\begin{abstract}
As the proposal of the Belt and Road Initiative, many companies and organizations send expatiates to the nations alongside the Belt and Road. Their training will play important role in the completion of projects. Focusing on language training, the paper will first analyze the basic knowledge about explicit and implicit learning system, then discuss the explicit and implicit approaches in expatriation training, and finally concluded by some feasible methods in training programs.
\end{abstract}

Keywords-expatriation training; communicative competence; implicit; explicit

\section{INTRODUCTION}

\section{A. Background}

The "Belt and Road Initiative" is a new trend for China's opening up, representing the economic development strategy of The Silk Road Economic Belt and the 21st-century Maritime Silk Road. Aimed for establishing and strengthening the partnership between China and the rest of Eurasia, the strategy may improve the efficiency of cross-border business communication and promote the economic and trade development in China.

Due to the growing frequent communications and exchanges, many international conglomerates pay more and more attention to training expatriates. After being selected, the expatriates will be professionally trained to ensure the efficiency and success of the company's projects. The training is particularly important for those who are going to be expatriated to foreign countries, where they may encounter various culture differences. A feasible training may improve the working efficiency and success rate of projects, which is vitally important to the quality and effect of the projects.

\section{B. Problems in Expatration Training}

However, most trainings lack of course books about English communication and culture conventions of the countries alongside the Belt and Road, and trainers rarely exchange their experience and cooperate with each other. Consequently, few training programs may receive satisfactory results, which further leads to the problems of high frustration quotient, low performance and high staff turnover [1].
Currently, the main content of the expatriation training is the quality of labor service and corporation management, language proficiency, and countries profile and culture [2][3]. Hereinto, the intercultural communicative competence and language proficiency has positive correlation with the performance of expatriates [4]. Besides, techniques, skills, the ability to analysis and make judgement, experience, value, culture, and code of conduct, which are the implicit knowledge, play a vital role in expatriates' performance but difficult to acquire [3]. In most programs culture and language are separately be trained and the latter is conducted in a very traditional way, which means the improvement in language proficiency does not promise the corresponding enhancement in communicative competence. Therefore, many people cannot effectively communicate after the language training. As the "Belt and Road Initiative" is newly proposed, and most researches are about intercultural communication of expatriates, few of them theoretically discuss the combination of language and intercultural communicative competence, and how to implicitly promote the training process. This paper will first analyze the basic knowledge about explicit and implicit learning system, then discuss the explicit and implicit approaches in expatriation training, and finally concluded by some feasible methods in training programs.

\section{THE BASIC KNOWLEDGE ABOUT EXPLICIT LEARNING AND IMPLICIT LEARNING}

Explicit and implicit learning is an important part of connectionism in people's knowledge acquisition. This section is going to introduce the explicit and implicit memory systems, and the differences between explicit and implicit knowledge.

\section{A. Explicit and Implicit Memory Systems}

Attributing to the recent researches on the brain, the existence of two distinct long-term memory systems - explicit memory and implicit memory-has commonly been accepted. Simply speaking, explicit memory is conscious memory while implicit memory unconscious. According to Schumann, explicit memory is associated with facts and events, and implicit memory is "memories for habits, motor and perceptual skills and emotional learning" [5:4], and can be "consciously recalled, represented, or verbalized" [5:5]. We can recall 
implicit memory automatically but we need some conscious efforts to recall explicit memory. Compared with explicit memory, implicit memory is more durable and less easily to be forgotten [6].

Supported by the theory of two memory systems, N. Ellis gives a specific definition of explicit learning and implicit learning in the following way:

Explicit learning is supported by neural system in the prefrontal cortex involved in attention, the conscious apperception of stimuli, and working memory; the consolidation of explicit memories involves neural systems in the hippocampus and related limbic structures. In contrast, implicit learning and memory are localized, among other places, in various areas of perceptual and motor cortex [7:121].

\section{B. Three Positions towards the Relationship between Explicit Knowledge and Implicit Knowledge}

The roles of explicit knowledge and implicit knowledge have caused many long-standing controversies in the field of second language acquisition (SLA). R. Ellis [8] identifies three different positions in studies about the relationship between explicit knowledge and implicit knowledge: the first one is the "non-interface position" represented by Krashen who believes that the two kinds of knowledge are totally distinct and "explicit knowledge cannot convert into implicit knowledge" [9:105]; the second one is the "strong interface position" proposed by De Keyser who holds that "explicit knowledge can convert into implicit knowledge" by practice [10:96]; and the last position is the "weak-interface position" put forward by R. Ellis who claims that explicit knowledge can be "a facilitator of the processes involved in the acquisition of implicit knowledge" [8:143].

\section{Non-interface position}

Krashen insists that learning cannot convert into acquiring and his theories show an obvious non-interface position [9]. He emphasizes the significance of subconscious acquisition in second language learning, and it helps obtain implicit knowledge which learners use to create spontaneous language performance. The explicit knowledge which learned through conscious effort, he thinks, can only be used as monitor to correct language. Thus, communicative learning approaches are supposed to be largely used in the classrooms. However, the non-interface position is not totally convincing: What Krashen believes that explicit learning is limited to some simple rules is challenged by Butler, Green and Hecht, who finds that adult learners can also learn complex [11] and substantial [12] rules. Green and Hecht also prove that sometimes explicitly learning a rule works more efficiently than acquire it implicitly (ibid)

\section{Strong interface position}

De Keyser puts forward another two terms "declarative knowledge" and "proceduralized knowledge" referring to explicit knowledge and implicit knowledge. His opinion is that "declarative knowledge" and "proceduralized knowledge" cannot separate from each other and explicit knowledge can pass into the acquired store by repeated language behavior [10] However, it is questioned by R. Ellis who doubts the equivalence between "proceduralized knowledge" and "implicit knowledge" [8:147].

\section{Weak-interface position}

R. Ellis develops a weak-interface model of SLA. Weakinterface position allows the mutual influence between explicit knowledge and implicit knowledge and focuses on the conditions that help explicit knowledge facilitate implicit knowledge. R. Ellis provides three possible ways according to the previous researches: enhancing input, hypothesizing in output and comparing it with input, and monitoring output [8:146].

N. Ellis also holds a weak-interface position, seeing a clear distinction between explicit knowledge and implicit knowledge, and insisting that explicit knowledge can be a facilitator of implicit knowledge.

The research specifies such distinction by identifying the relationship between the two kinds of knowledge that "a strengthening connections in the nondeclarative loop that is sometimes accompanied by a weakening of connections in the declarative loop" [6]. It denies the conversion between the two kinds of knowledge but supposes an increasing use of one memory system means a decreasing use of the other.

Another contributor of explicit and implicit learning theory is Bialystok, who allows a two-way interface between implicit and explicit knowledge. Her attitude towards the relation is complex. She thinks that unanalysed (implicit) knowledge can be the source of analysed (explicit) knowledge; at the same time, explicit knowledge can convert into implicit knowledge by practice [13]. That may explain why children do not know the reason for adding "-s" when they refer to something more than one at their early ages, but as they growing older, they would know by observation that adding "-s" is because of plural forms. Bialystok also states that unanalysed knowledge can be accessed through language behaviour like conversation. She breaks explicit knowledge down into analysed knowledge, which is about "L2 items and structures of which the learner is aware but not necessarily conscious" [14:144], and metalanguage, "the language used to analyze or describe a language" [15:144]. However, her view that language learning begins with unanalysed knowledge is challenged by the fact that many L2 learners starts by explicitly learning language knowledge [16].

\section{OPTIONS FOR EXPLICIT AND IMPLICIT WAYS IN EXPATRIATION TRAINING}

N. Ellis [7] gives a specific illustration of implicit learning and explicit learning:

Implicit learning is acquisition of knowledge about the underlying structure of a complex stimulus environment by a process which takes place naturally, simply, and without conscious operations. Explicit learning is a more conscious operation where the individual attends to particular aspects of the stimulus array and volunteers and tests hypotheses in a search for structure [7:121].

Due to the different attitudes towards explicit and implicit knowledge, different methods are used in expatriation training. 


\section{A. Preference for Implicit Methods}

Relatively few people insist on Krashen's implicit method in expatriation training. Lynch agrees with an implicit method that language should be studied by examining living speech rather than by analyzing written documents. Lynch also says it is important to expose trainees in context in an implicit way without "alienating" them to the language and the culture [17].

Fuller is another example. She claims that implicit method is simpler than explicit method. For instance, she mentions about learn language and familiarize culture through games. A new game can make a child an immediate participant. Children "know how to play the language game but have little awareness of the rules of that game" [18].

The biggest advantage of implicit learning method seems to be that students may acquire and use the knowledge in a very natural way, but the language accuracy becomes the problem that people concern most. N. Ellis takes the French immersion programme in Canada as an example, in which he states the disadvantage of such method in the development of language accuracy, and then demonstrates the need for explicit instructions [7:122].

\section{B. Preference for Explicit Methods}

Explicit method provides learners the specific information about rules to use language and then trainees can apply them in their daily usage. It is useful for learners to generate second language. After introducing language knowledge, learners are encouraged to make sentences, following the same structures and patterns. It seems to be more efficient, and more people show their preference for the explicit approach.

Stern [18:411] agrees that the "good language learner" employs explicit learning approach which highlights the usage of practice and memorization. Then the knowledge can be regarded as acquired knowledge. R. Ellis states that "an explicit presentation of rules supported by examples is the most effective way of presenting difficult new material" [16:643].

Scheffler and Cinciała [20] also encourage explicit methods to be used in language learning. They think there are at least two ways in which explicit language instruction can help with the implicit language development: One is that knowing explicit language rules, learners may "notice the structures that exemplify these rules in the input"; the other is that a better understanding of the rules underlying their own production "is a vital part of the learning process" for adults learners.

Ur further claims that implicit learning requires a lot of time and motivation, which are less available in a formal course of study. It means "leaning time has to be organized for optimum efficiency” [21:5].

However, on the question that how much explicitness should be provided, Lynch warns not to use strictly explicit language study and even language-focused lessons which are often not communicatively based. He thinks it might be "boring, cumbersome and difficult for students to assimilate...can be frustrating and highly ineffective" [17]. So obviously, totally explicit method is not appropriate for expatriation training.

\section{Explicit-Implicit Option}

Although the researchers mentioned above claim to prefer one of the two methods, we may find that actually explicit approach and implicit approach are not mutually exclusive, just as the relationship between the two kinds of knowledge, as they mention words like "communication", "notice", and "implicit manner". And that is also the opinion of the majority. Most people combine the two methods in language learning and teaching, just as Stern [22:128] puts that "there is no simple choice... We believe that both processes come into play and should be encouraged in a teaching programme". Harley and Swain also hold that comprehensible input alone is not enough for expatriation trainees, explicit language training is also needed [23:309]. Hammerly [24] maintains that both implicit method and explicit method have their place in language learning due to the fact that some rules suits better explicit way some other rules suits better another. It also explains why sometimes even trainers may not give a satisfied explanation of some complex language rules.

There are many concerns that trainers should take into account when combining explicit and implicit approaches.

There are four situations for choosing explicit or implicit approaches. First, explicit instruction works when the material to be learnt is simple. Second, implicit methods may get more efficiency when the material is randomly structured or some important relationships within the variables are not obvious [7]. Third, an explicit introduction to "patterns, regularities or underlying concepts of a complex problem" is better than implicit learning [25][26]. Last, some explicit knowledge can be operated in an unconscious way [27].

Nunan [28] agrees with an explicit-implicit ways in language learning. He says language should be taught in context so that learners may see the relationship between language and culture, form and function. He also encourages learners to discover the rules by themselves.

Furthermore, when to use explicit method or implicit approach also depends on the factors of expatriates themselves. Stern [22] noticed the education background of learners is an important factor. Language may mean less for language beginners than for advanced students, and highly educated learners show more need for language explanations and culture background than those with little schooling.

\section{SUGGESTIONS UNDERNEATH EXPLICIT AND IMPLICIT LEARNING THEORY}

Language training is one of the key parts in expatriate training, and should combine the explicit-implicit method with the knowledge on the Belt and Road Initiative. In this paper, the following three suggestions are proposed.

Firstly, expatriates should be trained in the Belt and Road Initiative related communication situations and introduced with the communication cases of different cultural situations. The language training cannot be confined to sentence practices. In order to enable the expatriates automatically output what they want to express in different communication situations, trainers have to put the language in certain contexts, thus trainees may select, output, experience and finally enhance their language 
proficiency and communicative competence. For example, the trainers may design a business negotiation case in which expatriates can analyze the culture difference, communication techniques, and business communication skills. In a word, expatriation training could utilize different methods to immerge trainees in the Belt and Road Initiative contexts and the language training could not be English culture-prominent.

Secondly, the training may involve some experienced returnees. The returnee refers to the expatriates who return to the company after finishing the projects abroad. Since the experienced returnees are usually equipped with a good global vision, rich experience in overseas market and good foreign language ability, they are quite instructive for an expatriation training program. Consequently, the human resource department could involve returnees in the expatriate training to help with the language training by instructing trainees with oversea living experience and practical language knowledge. In this way, the language skill and communicative competence may well be implicitly obtained.

Thirdly, training program designers may organize oversea internship for the trainers. Such language immersion training may allow expatriates to acquire language knowledge and culture in an implicit way which may correspondingly enhance their communicative competence. Trainers need to effectively integrate different social systems and functions to deal with the culture differences in an alien environment, so it may beneficial for cultivating objectiveness, interpersonal skill, international vision, and leadership. However, such programs always resort to costing a lot of revenue of a company, so for some organizations such programs are limited to executives or promising staff.

\section{CONCLUSION}

The Belt and Road Initiative has developed both in scope and in depth since its proposal. We will encounter many new problems and new challenges and higher requirements for expatriates are expected. Companies and institutions should train their expatriates in accordance with the demand of the Belt and Road Initiative, and carry out corresponding reforms. Specific training of communicative competence before leaving is necessary and need to combine with concrete context so that the language can be as authentic as possible. Purely teaching grammar rules and grammar structure is meaningless, language training should pay more attention to the development of expatriates' ability to communicate with foreign language in different situations. To avoid some predictable problems and unnecessary disputes in their future work, it would be better to well organize expatriation training program to prevent from progressing.

\section{REFERENCES}

[1] Y. H. Zhou, and X. J. Cui, Influence of Employee Social Network on Expatiate and the Adjustment Effects of Culture Distance, Journal of Hebei University of Economics and Business, 2012,vol.33, no.5.

[2] Q. Yang, On the Importance of Expatriation Training, Ability and Wisdom, 2014, vol.3.

[3] X.J. Xu, Impact of Expatriates' Intercultural Communication Competence on Their Task Performance: Mediating Effect of
Professional Knowledge Learning, Research and Development Management, 2016, vol.28, no.4.

[4] J. W. Zhu and W. M. Hu, Expatriates, Communication Satisfaction and Knowledge Transfer Capacity-An Empirical Analysis Based on Multinational Corporations in China, East China Economic Management, 2015, vol.29, no.6.

[5] J.H. Schumann, The Neurobiology of Learning: Perspectives From Second Language Acquisition. Oxford: Oxford University Press, 2004.

[6] Implicit and Explicit Learning in Second Language Acquisition: An Introduction. "Language and the Learner" Moray House School of Education, 2010.

[7] N. Ellis, Implicit and Explicit Knowledge about Language In: J. Cenoz, and N. H. Hornberger, (eds) Encyclopedia of Language and Education 2nd ed. New York: Springer Science, 2008.

[8] R. Ellis, Explicit Knowledge and Second Language Learning and Pedagogy In: J. Cenoz, and N. H. Hornberger, (eds) Encyclopedia of Language and Education 2nd ed. New York: Springer Science, 2008.

[9] S. Krashen, Principles and Practice in Second Language Acquisition. Oxford: Pergamon, 1982.

[10] R. De Keyser, 'Beyond focus on form: Cognitive perspectives on learning and practicing second language grammar', in C. Doughty and J. Williams (eds.), Focus on Form in Second Language Acquisition, Cambridge : Cambridge University Press, 1998: 42-63.

[11] Y. Butler, Second Language Learners' Theories on the Use of English Articles, Studies in Second Language Acquisition, 2002, vol. 24.

[12] P. Green, and K. Hecht, Implicit and Explicit Grammar: An Empirical Study, Applied Linguisitics 1992: vol.13.

[13] E. Bialystok, A Theoretical Model of Second Language Learning, Language Learning, 1978: vol.28, pp.69-84.

[14] E. Bialystok, 'Representation and Ways of Knowing: Three Issues in Second Language Acquisition', in N. Ellis (ed.), Implicit and Explicit Learning of Languages, London: Academic Press, 1994, pp.549-569.

[15] J. Richards, J. Platt, and H. Weber, Longman Dictionary of Applied Linguistics, Longman, London.1985.

[16] R. Ellis, The Study of Second Language Acquisition. Oxford: Oxford University Press, 1994.

[17] L.M. Lynch, Grammar Teaching: Implicit or Explicit? http://www.eslbase.com/articles/grammar-implicit-explicit accessed $12 / 05 / 2017$

[18] R. Fuller, Implicit versus Explicit Learning-The Ability to Play the Game versus Knowing the Rules of the Game http://www.ballstickbird.com/articles/a5 implc.html accessed $01 / 05 / 2016$

[19] H. H. Stern, Fundamental Concepts of Language Teaching Oxford: Oxford University Press, 1983.

[20] P. Scheffler, and M. Cinciała, Explicit Grammar Rules and L2 Acquisition, ELT Journal 2011, vol. 65(1).

[21] P. Ur, Grammar Practice Activities: A Practice Guide for Teachers Cambridge: Cambridge University Press, 1988.

[22] H. H.Stern, Issues and Options in Language Teaching Oxford: Oxford University Press, 1992.

[23] B. Harley, and M. Swain, The Interlanguage of Immersion Students and Its Implications for Second Language Teaching In A. Davies, C. Criper, and A. R. Howatt, (eds) Interlanguage Edinburgh: Edinburgh University Press, 1984.

[24] H. Hammerly, The Deduction Induction Controversy Modern Language Journal, 1975, vol. 59

[25] B. Mac Whinney, Implicit and Explicit Processes, Studies in Second Language Acquisition, 1997, vol.19.

[26] A. Reber, S. Kassin, S. Lewis, and G. W. Cantor, On the Relationship between Implicit and Explicit Modes in the Learning of a Complex Rule Structure Journal of Experimental Psychology, 1980, vol. 6.

[27] M. A. Stadler, and P. A. Frensch, (eds) Implicit Learning Hangbook. CA: Sage Publications, 1998

[28] D. Nunan, Teaching Grammar in Context, ELT Journal. 1998, vol. 53(2). 